En esta primera entrega dedicada a la salud bucal, se hará un repaso acerca de la erupción dentaria, la dentición primaria y definitiva; y luego se abordarán la fisiopatología y factores de riesgo, la prevención, el diagnóstico y el tratamiento de la caries. La segunda entrega será dedicada principalmente a la enfermedad periodontal.

\section{Erupción dentaria}

\section{Dentición primaria}

Los dientes primarios (vulgarmente conocidos en Argentina como "de leche") comienzan a erupcionar entre los cuatro y los 12 meses de edad (promedio seis). Los incisivos centrales son generalmente los primeros, seguidos por los laterales, luego por los caninos y, por último, por los primeros y segundos molares. Los dientes mandibulares erupcionan uno o dos meses antes que los maxilares; completándose la dentición primaria completa a los tres años de edad y encontrándose en cada arcada dentaria cuatro incisivos, dos caninos y cuatro molares. Los espacios entre los dientes primarios pueden ser mas amplios que los de la dentadura definitiva. Ver figura 1

Los retardos en la erupción generalmente se asocian a otros trastornos del desarrollo, alteraciones nutricionales, síndrome de Down, hipopituitarismo, hipotiroidismo, etc

Se recomienda que el médico de atención primaria controle que l niño posea las 20 piezas a los tres años de edad, que éstas no estén malformadas y/o mal alineadas y que no tengan caries; interconsultando al odontólogo cualquier irregularidad.

Varios síntomas pueden acompañar a la erupción, siendo la febrícula el babeo y la irritabilidad los más comúnmente encontrados. En general, no se observan signos al examen físico, pudiendo identificarse a veces el llamado "hematoma de la erupción", que se trata de un quiste sanguíneo de color azulado que drena espontáneamente con la erupción. La incomodidad puede reducirse aplicando localmente un paño frío o hielo. No se recomiendan los preparados que contienen anestésicos locales de uso tópico por el riesgo de intoxicaciones. Teniendo en cuenta que muchas entidades comunes (ej. infecciones respiratorias altas, otitis, diarreas) pueden coincidir con la aparición de los dientes, la fiebre alta o los signos de compromiso sistémico no deben ser atribuídos a la erupción, requiriendo una cuidadosa evaluación de su origen en todos los casos.

\section{Dentición permanente}

La dentición permanente comienza entre los seis y siete años de edad con la aparición de los incisivos y del primer molar permanente. Este último aparece sin que se pierda ningún otro, lo cual pasa inadvertido por la familia. Se debe explicar que este diente es definitivo y requiere ser cuidado. El segundo molar suele apare- cer a los 12 años de edad y el tercero, a los 18. La secuencia de erupción de las piezas definitivas no está sujeta a un orden estricto, por lo tanto las alteraciones en el orden de aparición no implican la presencia de patología 1 .

\section{Caries}

La caries es una enfermedad crónica, infecciosa y multifactorial. Es la más común de la boca y del ser humano, comienza temprano luego de la erupción de los primeros dientes, incrementándose su incidencia con la edad. Se genera por la combinación de varios factores: mala higiene bucal, poco aporte de flúor, presencia de bacterias (las más importantes son el Streptococcus mutans y Lactobacillus) y altos contenidos de hidratos de carbono en la alimentación. La falta de tratamiento lleva a la pérdida dentaria y a la enfermedad de los tejidos duros de la boca con la ineludible repercusión en la nutrición la mímica y la estética de los pacientes afectados.

\section{Epidemiología}

En los niños y adultos jóvenes la superficie del diente más afectadas son las caras con poros, las fisuras anatómicas y las caras oclusales; en los adultos, las caras lisas (anterior y posterior) mientras que en la población anciana se incrementa la presencia de caries de la raíz dental. Una forma particular es la caries de la primera dentición, entidad que afecta primordialmente a los dientes de la arcada superior, los anteriores y, raras veces, los posteriores. a prevalencia es particularmente alta en los grupo aborígenes de América, no superando el $5 \%$ en la población general. Si bien estas conclusiones provienen de estudios de diseño pobre 2,3 varios reportes sugieren que se generan por el contacto prolongado entre fluídos con alto contenido de azúcar y los dientes del niño, especialmente en las niños que prolongan la alimentación nocturna mas allá de los seis meses o en los que se duermen con la mamadera En cuanto a la distribución de esta entidad existen grandes diferencias regionales. Los países desarrollados han disminuido en un 33 a $50 \%$ la prevalencia e incidencia de caries en los últimos 30 años en los niños y adultos jóvenes. En adultos, estudios más recientes evidencian que la actividad cariogénica no ha variado mucho pero sí se observa una disminución del número de piezas dentarias caídas y arregladas. Esto sin duda se debe a que la población que en la década de 1990 tenía 30 a 50 años de edad es la misma que comenzó a cambiar sus hábitos de higiene bucal y a recibir flúor en el agua corriente, condiciones que comenzaron a practicarse hace 30 años y que habrían permitido que esta generación alcance la edad adulta con mejor estado dental que las anteriores. Luego de los 40 años de edad indicadores vuelven a empeorar y se cree que en esta población la actividad cariogénica mantendría debido a la caída de los arreglos que se habían practicado anteriormente.

En los países en vías de desarrollo la prevalencia de caries es muy

Figura 1

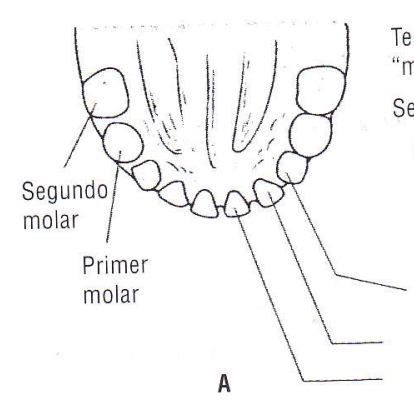

Tercer molar definitivo 0 "muela del juicio" Segundo molar definitivo

Primer molar definitivo Segundo premolar

Primer premolar Canino

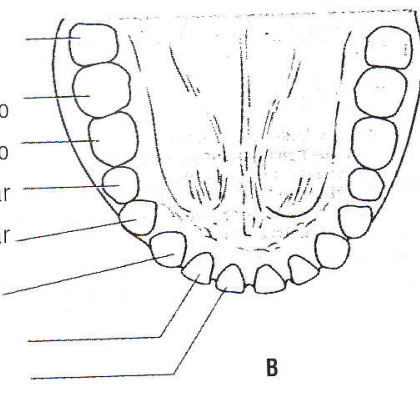


superior, favoreciendo esta condición múltiples factores: alimentarios, higiénicos, culturales y económicos.4,5

\section{Factores de riesgo para el desarrollo de caries}

1. Condiciones médicas: todas aquellas enfermedades que generen trastornos de la cantidad y la calidad de la saliva como el síndrome de Sjögren y otras enfermedades autoinmunes, la bulimia, la diabetes y la anemia perniciosa; el uso de medicación o quimioterapia que genere xerostomía, así como la irradiación de la cabeza y el cuello; las enfermedades ortopédicas que generen dificultades para la higiene bucal, las neurológicas que afecten e movimiento sincronizado o generen debilidad mental, las coagulopatías, las neutropenias, etc.

2. Condiciones del paciente: pobre higiene oral y dietas ricas en hidratos de carbono.

3. Condiciones dentarias: antecedentes de caries antes de los cinco años de edad, antecedentes de caries en los dientes anteriores, actividad cariogénica intensa desarrollada entre los distintos controles odontológicos, alto número de piezas dentarias caídas y arreglos en los dientes posteriores, altos niveles de bacterias cariogénicas (más de 750.000UFC de Streptococcus mutans o más de 100.000UFC de Lactobacillus por $\mathrm{mL}$ de saliva) lesiones gingivales y caries de la raíz dentaria.

\section{Fisiopatología}

La posibilidad de la formación de caries está regida por un equilibrio entre las agresiones (ácidos bacterianos con acción desmineralizante sobre los dientes) y los mecanismos de protección (cepillado y presencia de flúor). Es un proceso dinámico entre los factores que favorecen la desmineralización del diente y la remineralización. Si la desmineralización es favorecida se forman pequeñas cavidades en la superficie dentaria donde se depositan las bacterias y se favorece el crecimiento de la placa.

La composición, calidad y frecuencia de la alimentación tiene influencias locales en la cavidad oral. La boca está colonizada por una microflora variada, siendo el metabolismo de estas bacterias particularmente activado por los azúcares de la dieta. Si el individuo ingiere azúcares en forma repetida las bacterias sintetizan los proteoglicanos que les sirven de sustratos para adherirse al diente formándose así la placa bacteriana que, rápidamente, aumentará de volumen. Una vez adheridas, las bacterias sintetizan sustancias ácidas, principalmente ácido láctico, con efecto desmineralizante sobre el diente. La saliva actúa como "buffer" neutralizando los ácidos bacterianos, mientras que los minerales que ésta contiene pueden rellenar los microporos que el ácido provoca. Cuando la ingesta de azúcar se limita a cuatro comidas diarias el ácido es contrarrestado, pero cuando la ingesta es mayor este mecanismo compensatorio no alcanza y el balance se inclina hacia la desmineralización. Si además el paciente no cepilla sus dientes ni usa hilo dental la placa bacteriana crecerá.

El cepillado es importante porque además de barrer la placa bacteriana de dientes y encías aporta flúor con el dentífrico, lo que acelera considerablemente la velocidad de remineralización del esmalte dentario

Antes se creía que la ingesta repetida de azúcar era un factor de riesgo independiente para la generación de caries, estudios recientes han demostrado que el hábito del consumo de azúcar se asocia a caries sólo en presencia de malas condiciones de higiene (la ingesta de azúcar en cantidades excesivas acompañada de una prudente higiene bucal no se relacionó con mayor producción de caries en la población general).

\section{Prevención de las caries}

Flúor

Al combinarse con los cristales de hidroxiapatita, el flúor forma un complejo que es más resistente a la desmineralización del diente cuando hay un ataque ácido.

La fluoración de las aguas es la forma más simple, efectiva, segura, (porque no tiene riesgo de intoxicación ni de efectos adversos) económica y equitativa para prevenir caries de raíz y de corona. Varios trabajos 6 han mostrado que esta estrategia de prevención reduce 60 a $70 \%$ la incidencia de caries y 10 a $30 \%$ la de caídas de piezas dentarias. La concentración adecuada para la prevención es de 0,8 a 1,2 partículas por millón (ppm), no generando mejores beneficios concentraciones superiores (sólo aumentan el riesgo de fluorosis dental)

En las áreas geográficas donde la concentración de flúor en el agua es menor a 0,3ppm, el aporte se puede realizar por medio de suplementos como dentífricos, topicaciones, gotas, comprimidos, enjuagues bucales, etc. La figura 2 ilustra las distintas concentraciones de fluor en el agua en Argentina.

Las topicaciones deben ser practicadas por el odontólogo, siendo la forma más difundida la que se realiza con fosfato-fluor-acidulado al 1,23\% con un ph de 3,1. Pueden ser aplicadas con cubetas de $4 \mathrm{ml}$ o hisopos, pudiéndose utilizar tambien geles de fosfatoflúor-acidulado con una concentración al $1 \%$ y un ph de 5,6. Vale aclarar que este tipo de presentación es similar al de las pastas dentales y como su venta es libre puede ser confundida con un dentífrico y usado como tal. Como contiene alto contenido de flúor su ingesta puede ocasionar intoxicaciones graves hasta la muerte. Aún no hay acuerdo sobre la frecuencia en que se debe aplicar, recomendándose una aplicación cada uno o dos años.

Los enjuagatorios fluorados, compuestos por fluoruro de sodio, se pueden administrar diariamente al 0,05\% (230ppm de flúor) o bien,

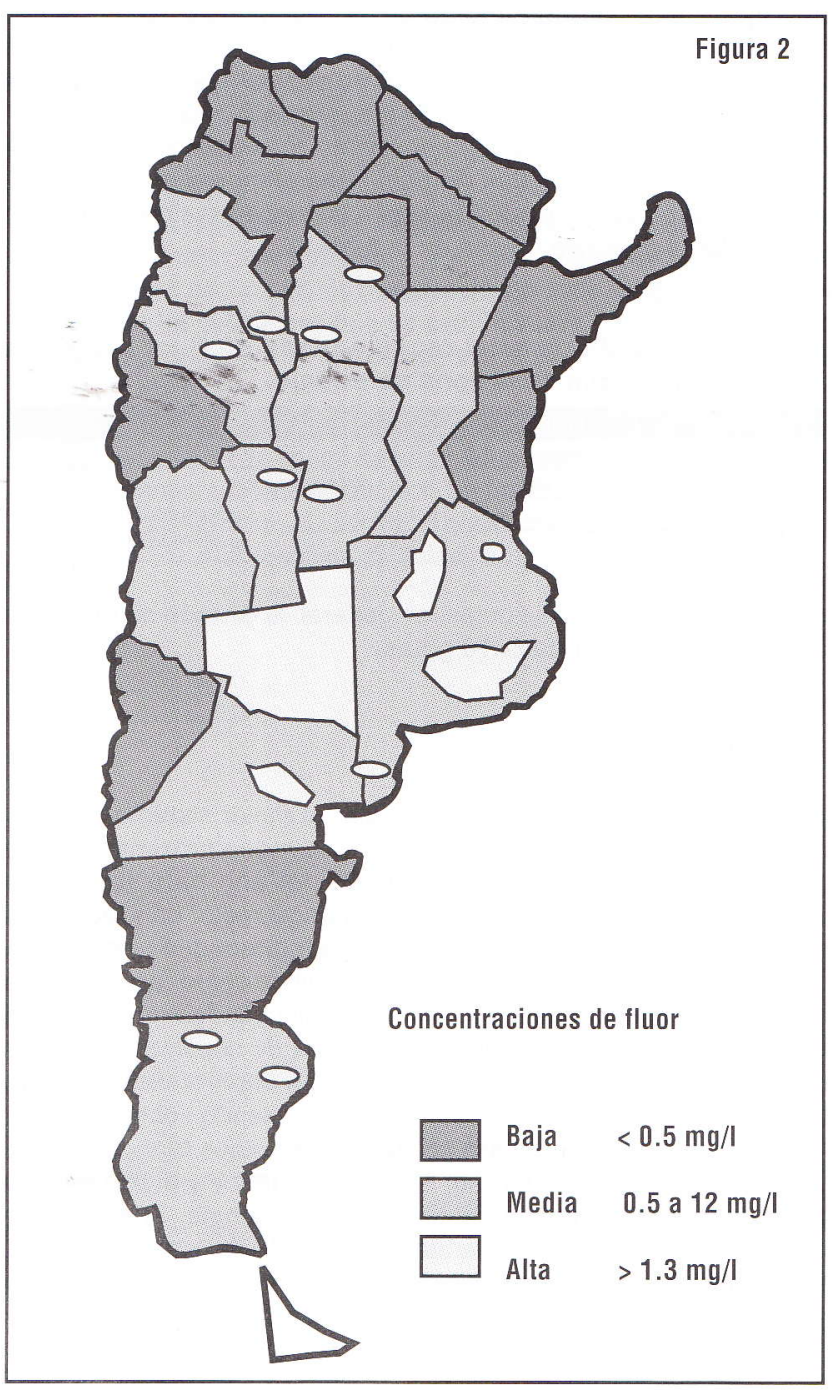


con periodicidad quincenal al 0,2\% (900ppm de flúor). Su efecto depende de cuatro factores: 1) la edad (a menor edad, mayor es la cantidad de enjuagatorio retenido); 2) tiempo de duración del buche (a mayor duración, mayor retención); 3) volumen (a mayor volumen, mayor retención); 4) experiencia previa con los enjuagatorios (a mayor experiencia, menor retención). Por todas estas razones no se recomienda su empleo en niños preescolares. Los niños de edad escolar que los requieran deben ser supervisados por los padres. El buche debe durar 45 a 60 segundos y luego debe ser totalmente descartado. Una vez desechado no se debe enjuagar ni cepillar los dientes.

Pastas dentales: la mayoría de los dentífricos poseen entre 1000 y 1100 ppm de flúor. Varios estudios demuestran que los niños menores de seis años tragan gran cantidad de flúor al usarlos. Se recomienda que los menores de seis años no usen dentífricos con altas concentraciones de flúor y que se cepillen bajo la supervisión de sus padres. Los padres deben proveer el cepillo con poca cantidad de pasta (como un poroto) y es conveniente utilizar productos que no contengan mejoradores del sabor para no favorecer su ingestión. Es importante enseñar a los niños a enjuagarse vigorosamente después del cepillado. Si bien ningún trabajo demostró que la supervisión del cepillado reduzca la cantidad de pasta ingerida, esta acción llevaría a la limitación de la cantidad de pasta aportada en el cepillo.?

La fluoración de leches y sales no se utilizan porque es muy difícil controlar su dosificación.

Las gotas y comprimidos son las formas más fáciles de administrar el flúor en los menores de seis años. Varios estudios han demostrado que su utilización indiscriminada, sin tener en cuenta los niveles de flúor en el agua local, aumenta la incidencia de fluorosis dental, por lo tanto antes de recomendar estas formas farmacológicas se debe tener en cuenta el nivel de flúor en el agua local. La administración oral de fluor no debe ser recomendada en áreas con fluoración de aguas de mayores a $0,7 \mathrm{ppm}$.

De acuerdo a lo expresado anteriormente, los suplementos de flúor pueden ser recomendados en pacientes menores de seis años, debiendo la dosis ser evaluada según la concentración de flúor en el agua local como se detalla en la tabla 1.

Tabla 1: Dosis diaria total recomendada de fluor según la fluoración del agua de la zona de trabajo.

\begin{tabular}{l|l|l|l}
\hline Edad en aíos & \multicolumn{3}{|c}{ Contenido de flíor en el agua (ppm) } \\
\hline & Menos de 0,3 & 0,3 a 0,7 & 0,7 a 1,2 \\
\hline Menos de 2 & $0,25 \mathrm{mg}$ & \multicolumn{2}{|c}{ No suplementar } \\
\hline 2 a 3 & $0,5 \mathrm{mg}$ & $0,25 \mathrm{mg}$ & No suplementar \\
\hline 3 a 6 & $1 \mathrm{mg}$ & $0,5 \mathrm{mg}$ & No suplementar \\
\hline
\end{tabular}

En la presentación de las gotas, en general, la dilución corresponde a $0,5 \mathrm{mg}$ de flúor por cada 10 gotas.

\section{Cepillado e hilo dental}

El cepillado y el uso de hilo dental son el mejor sistema para remover la placa bacteriana. Debe ser renovado aproximadamente cada tres meses (con cada estación del año para facilitar el recuerdo). El mejor modelo es el de mango recto, con todas sus cerdas de nylon y de la misma altura, de manera que terminen en un solo plano. Existen otros tipos de cepillos como los eléctricos que son recomendados a pacientes con dificultades motoras para el cepillado manual. No existe una técnica de cepillado que haya demostrado ser más efectiva que otras. Lo importante es cepillar todas las caras del diente y las encías, ejerciendo sobre la superficie una presión suave para no dañar los tejidos blandos. Cada sector debe cepillarse durante 10 a 15 segundos y el movimiento debe abarcar aproximadamente dos o tres dientes. El movimiento puede hacerse circular, paralelo o vertical a la arcada dentaria recomendándose que en los incisivos y caninos se use la posición vertical para las caras linguales ya que la forma de cepillado vertical tiene la ventaja que ayuda a barrer los restos de comida del espacio interdentario.

No hay acuerdo de cual es la frecuencia mínima efectiva para la remoción de la placa bacteriana y la prevención de la caries. Se recomienda cepillarse los dientes tres veces por día con dentífricos recomienda cepillarse losible, cepillar dos veces al día, siendo los momentos más apropiados: después de la cena y del desayuno. momentos maños menores de doños limpiar los dientes con un paño húmedo o un cepillo suave para barrer la placa bacteriana por lo menos una vez al día desde el momento de la erupción. El cepillado debe iniciarse luego de los dos años bajo la supervisión de los padres con reducida cantidad de dentífrico y cuidando que no lo ingieran.

El hilo dental es tan importante como el cepillado porque puede penetrar en zonas interdentarias donde el cepillo no puede llegar, barriendo la placa bacteriana y eliminando los restos de alimentos. Para su uso debe enrollarse en los dos dedos índices de las manos y ubicar en cada uno de los espacios interdentarios realizando movimientos de adelante hacia atrás y de arriba hacia abajo, cuidando de no lastimar las encías. Ver figura 3.

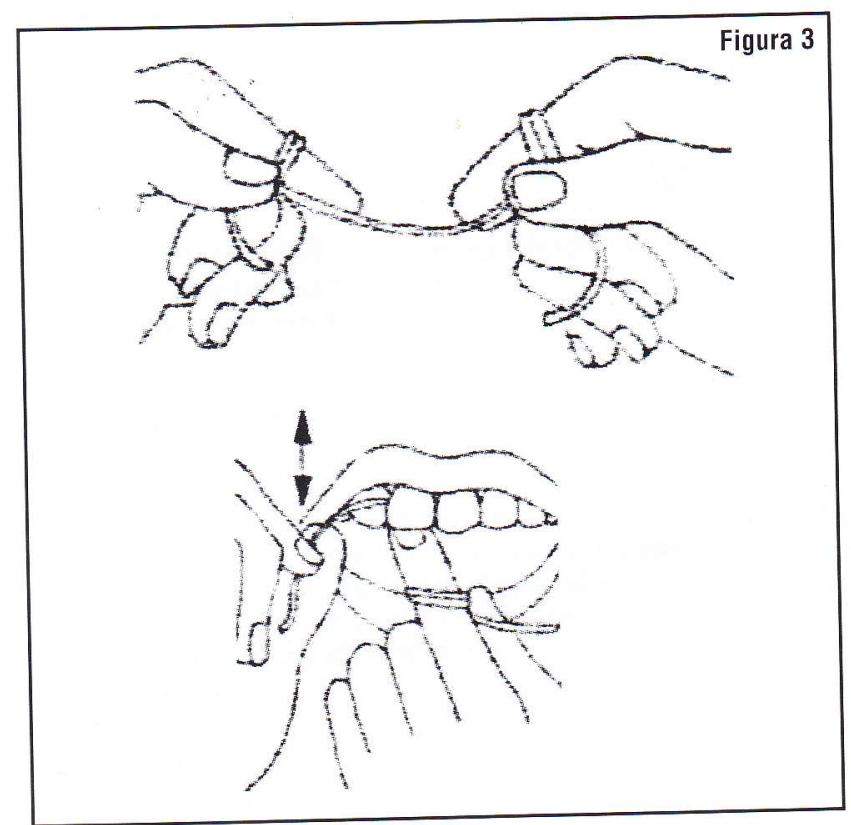

\section{Consejos dietarios}

Hasta hace poco se pensaba que toda persona que tenía el hábito de ingerir alimentos altamente azucarados en forma repetida y fuera del horario de las comidas tenía más riesgo de caries. Sin embargo, los resultados de los últimos trabajos confirman que las caries aparecen solo en aquellos que no poseen hábitos de higiene bucal adecuados. Por eso, hoy en día la indicación de restringir la ingesta de alimentos con altas concentraciones de azúcar con el único motivo de prevenir las caries está limitada a los pacientes con alto riesgo de desarrollarla mencionados previamente en los grupos de riesgo. ${ }^{1}$

Por la mismo razón existe controversia sobre los consejos dietarios en los niños. Sin embargo los expertos recomiendan que luego de los seis meses de edad se restrinja el contacto con el biberón luego de los horarios de alimentación, evitar que el niño se duerma con el biberón o el pecho en la boca, la lactancia a voluntad durante la noche, endulzado de la tetina y chupetes, así como el consumo de golosinas y gaseosas.

El siguiente cuadro 1 resume la evidencia que avala las distintas intervenciones propuestas para la prevención de las caries. 


\section{Cuadro 1: recomendaciones para la prevención de caries}

- El uso de aguas fluoradas con una concentración de 0,8 a 1,2ppm: recomendación tipo $A$.

- El uso de dentífricos fluorados y suplementos fluorados en poblaciones donde el agua corriente posee una concentración de flúor menor a $0,3 \mathrm{ppm}$ : recomendación tipo A.

- En pacientes con pérdida de varias piezas dentarias $y / 0$ factores de riesgo para caries, en quienes por factores físicos no pueden realizar las maniobras de higiene bucal (neurológicos, ortopédicos, coagulopatías, neutropénicos, etc) se recomienda la aplicación tópica de flúor por odontólogos o el uso de soluciones para enjuague bucal: recomendación tipo $\mathrm{A}$.

- El uso de aplicaciones tópicas de flúor o el uso de enjuague bucal con soluciones ricas en flúor en la población general: recomendación tipo C.

- Hay suficiente evidencia en contra de realizar limpieza dentaria profesional antes de la aplicación del flúor tópico y del uso de enjuagues bucales: recomendación tipo $\mathrm{D}$.

- Hay pobre evidencia para recomendar la limpieza profesional para la prevención de caries: recomendación tipo C (sin embargo, sí la hay para la prevención de la gingivitis y la enfermedad periodontal a través de la limpieza y curetaje del sarro).

- Hay pobre evidencia para recomendar el cepillado y el uso de hilo dental estricto en la prevención de caries: recomendación tipo C (sín embargo se debe recomendar el cepillado para la aplicación de flúor, así como el cepillado y uso de hilo dental con el objetivo de prevenir la gingivitis y la enfermedad periodontal).

- Hay buena evidencia para la aplicación de selladores de fisuras en los molares permanentes de niños que tienen factores de riesgo para caries: recomendación tipo A.

- No hay suficiente evidencia para recomendar el cambio de hábito dietario en la población general con el objetivo de prevenir el desarrollo de caries, ni para restringir el uso prolongado de biberones con leche u otros líquidos en lactantes: recomendación tipo C.

Fuerza de la recomendación A, clara evidencia a favor, B evidencia a favor, C, ni a favor ni en contra, D evidencia en contra

\section{Resúmen para Ilevar al consultorio}

- La caries es la enfermedad más común de la boca, comienza luego de la erupción de los primeros dientes y se genera por la interrelación de mala higiene bucal, poco aporte de flúor, presencia de bacterias y alto contenido de hidratos de carbono en la alimentación.

- En los países desarrollados durante los últimos 30 años la prevalencia e incidencia de caries en niños y adultos jóvenes ha disminuido en un 33 a $50 \%$.

- La fluoración de las aguas es la forma más simple, efectiva, segura, económica y equitativa para prevenir caries de raíz y de corona. En regiones donde la concentración de flúor en el agua es menor a $0,3 \mathrm{ppm}$, el aporte se puede realizar por medio de suplementos (dentífricos, topicaciones, gotas, comprimidos, enjuagues bucales, etc.).

- El uso ind iscriminado de suplementos orales de fluor sin tener en cuenta los niveles de fluoración de las aguas aumenta la incidencia de fluorosis dental, no recomendándose su administración oral si la concentración en el agua corriente supera las $0,7 \mathrm{ppm}$.

- El cepillado barre la placa bacteriana de dientes y encías y aporta flúor con el dentífrico, lo que acelera considerablemente la velocidad de remineralización del esmalte dentario y forma un complejo más resistente. El hilo dental permite penetrar en zonas interdentarias donde el cepillo no puede llegar.

- Controlar que el niño posea las 20 piezas a los tres años de edad, que éstas no estén malformadas y/o mal alineadas y que no tengan caries.

- No atribuir a la erupción dentaria fiebre alta o signos de compromiso sistémico.

- Cepillar cada sector de la dentadura durante 10 a 15 segundos, abarcando el movimiento dos o tres dientes. Recorrer todas las caras del diente y las encías, ejerciendo sobre la superficie una presión suave para no dañar los tejidos blandos. - Que los menores de seis años no usen dentífricos con altas concentraciones de flúor y que se cepillen bajo la supervisión de sus padres. En los menores de dos años, limpiar los dientes con un paño húmedo o un cepillo suave para barrer la placa bacteriana por lo menos una vez al día desde el momento de la erupción.

- Después de los seis meses de edad, evitar el contacto con el biberón luego de los horarios de alimentación, que el niño se duerma con el biberón o el pecho en la boca, la lactancia a voluntad durante la noche, el endulzado de la tetina y chupetes, así como el consumo de golosinas y gaseosas. 